\title{
THE ROLE OF STRATEGIC LEADERSHIP IN STIMULATING TOURISM IN JORDAN
}

\author{
Mohammad Shabib KHASAWNEH* \\ Al-Balqa Applied University, Ajloun College, Tourism Management Department, Ajloun, Jordan, e-mail: khasawnehmohammad79@bau.edu.jo
}

Citation: Khasawneh, M.S. (2020). THE ROLE OF STRATEGIC LEADERSHIP IN STIMULATING TOURISM IN JORDAN. GeoJournal of Tourism and Geosites, 32(4), 1384-1387. https://doi.org/10.30892/gtg.32428-584

\begin{abstract}
The study aimed to uncover the relationship between adopting the strategic leadership approach and enhancing the competitive advantage of the tourism sector in Jordan. To meet this goal, the viewpoint of a sample of (20) people who have extensive exp erience in the field of strategic planning and strategic management was surveyed. The results of the main hypothesis test showed a positive correlation between adopting the strategic leadership approach and enhancing the competitiveness of the Jordanian tourism sector.The study recommended the necessity of training leaders in the Ministry of Tourism on the strategic approach and the necessity of adopting strategic planning as a basic option to enhance the competitiveness of tourism in Jordan.
\end{abstract}

Key words: strategic leadership, enhancing competitiveness, tourism sector, stimulating tourism, Jordan

$* \quad * * * * *$

\section{INTRODUCTION}

Tourism organizations seek to take advantage of modern administrative methods and models to be able to adapt to the changes occurring in the tourism business environments to be able to discuss the deficiencies in financial capabilities and raise the levels of performance and level of services provided by the organizations to achieve outstanding the success that helps them achieve the progress and achievement that they seek to meet. Boljević, et al. (2014) Tourism is a labor-intensive economic activity that provides more than 200 million jobs worldwide. The share of tourism in global GDP is about $10.5 \%$, through tourism more than $12.5 \%$ of the world's total exports and about $30 \%$ of global trade in services are generated. Vukotic and Vojnovic (2016) confirm that comprehensive tourism development in the modern era is directed to the maximum extent towards tourists, customers, and their satisfaction, and thus it is one of the most profitable industries in the world and has great economic importance for each country. The higher the general level of development, the more important the position and role of this group of the services sector, and this require the adoption of a strategic management approach to achieve competitive advantage. Strategic management is one of the most prominent modern management models as an organized process that includes evaluation, planning, and implementation designed to support or improve the competitive advantage by analyzing factors affecting the internal and external environments of organizations (Hitt et al., 2012, McGee et al., 2010; Sammut, 2010).

Strategic leadership plays an effective role that affects all activities of the organization, as it contributes to creating the proper organizational climate, which affects employee satisfaction. Consequently, it contributes to providing an administrative environment that helps make individual, group, and organizational goals. Consequently, it affects the effectiveness or performance of individuals, groups, and the entire organization and requires attention to leadership development (Zhang and Li, 2013).

According to (Harrington and Ottenbacher, 2013), the importance of strategic management and strategic thinking in the areas of tourism lies in its ability to deal with the increasing turmoil in the global environment by providing strategic solutions to meet current and future challenges and opportunities. To achieve a competitive advantage in the tourism sector, it is necessary to uncover potential opportunities or potential dangers, in addition to strengthening powers and avoiding weaknesses, all of which could be benefits of planning for future development efforts. This requires tourism planners to take unforeseen circumstances and unforeseen constraints into account when developing the strategic plan (Ketchen and Short, 2011). In Jordan, a strategic planning unit was created to be a source for setting goals related to all aspects of tourism activity, organizing human resources management in particular and following policies to allow workers, accurately characterizing the performance of the tourism business and specific criteria for measuring the performance gap in the tourism sector. The goal of this unit was to adopt strategic planning for the tourism sector in Jordan so that there is a series of operations that the strategic planning unit carries out to define its future vision, then take the necessary decisions to give the required allocations for their implementation and follow-up their activation, taking into account the internal and external environment factors that affect tourism activity. The Jordanian Ministry of Tourism has defined its strategic vision by strengthening tourism marketing, supporting competitiveness and developing the tourism product, enhancing human resources, and providing an effective institutional and organizational framework. The study seeks to know the effect of the dimensions of the strategic leadership in revitalizing the tourism sector in Jordan, as the study tests the following main hypothesis:

There is a statistically significant effect at the level of $(\alpha<05.0)$ of the strategic leadership on the revitalization of tourism in Jordan.

\section{PREVIOUS LITERATURE}

Hamtick's, 2002; Covey, 2006; Wagen, 2006; Dalton et al., 2000 management literature agrees that strategic leadership is one of the modern administrative methods as a process by which public administration can define the long-term directions of the organization, as well as performance through the right design, appropriate implementation, and continuous evaluation of the strategy developed, and This process consists of several elements that complement each other and these elements are defining the mission of goals, the field of action, developing and implementing strategies and its evaluation. According to (Olson and Shobe, 2008) strategic leadership reflects the ability of the organization's management to properly align with the driving forces of change in the environment of the Competition Company. This requires a structure capable of monitoring and managing the effective recruitment of resources through a process capable of distinguishing between opportunities add value with the overall goal of achieving a competitive advantage in the market.

David, 2005; Capon, 2008; Enz, 2010; Pisapia, 2009 define that strategic leadership has four main dimensions:

1. The administrative dimension, as this dimension contributes to the investment of material and human capabilities to achieve organizational goals.

\footnotetext{
${ }^{*}$ Corresponding author
} 
2. Transformational dimension: the importance of this dimension is that it helps the leader achieve goals in unstable environments.

3. The political dimension: this dimension contributes to convincing the higher leaders of the importance of strategic plans in facing the challenges of internal and external environments.

4. The ethical dimension: as the strategy-making, implementation and evaluation includes an ethical dimension, the strategic leader is responsible for establishing ethical principles within the organization.

Despite the importance of strategic leadership in the tourism sector (Harrington et al., 2011) confirms that the summary of administrative literature in the period from (1980-1999) shows that models related to strategic leadership were developed in sectors other than the tourism sector, then it applied to the tourism industry. However, starting in the year 2000, organizations of all kinds began to move towards the application of strategic management in various institutions by adopting new models to reveal the real effects of implementing strategic leadership (Hmieleski et al., 2006; Danneels, 2011; Chatain, 2011). Developments in the strategic literature have had an impact on the literature and research of hospitality and tourism strategy. Hospitality and tourism strategy research is becoming more nuanced and complex with an increased focus on the relationships specific to the hospitality and tourism context while elucidating these relationships. These results are reflected in the following sections using the strategy categories as in the previous timeframe section (Harrington et al., 2011).

Many researchers tried to uncover the relationship between adopting the strategic leadership approach and increasing the competitiveness of the tourism sectors. The study by (Chatain, 2011) confirmed the existence of a strong relationship between adopting strategic leadership and increasing competitiveness in the restaurant sector in the United States of America (Tavitiyaman et al., 2012). The Impact of Competitive Strategies on the Performance of Hotel Companies. The study showed that the strategic leadership of human resources had a direct impact on the competitive performance of tourism companies.

\section{Study Approach}

The researcher used the descriptive survey approach, given its suitability for the purposes of the study, and the use of the descriptive approach in this study is clear by collecting data, information, and data to show the relationship between the practice of strategic management and the activation of tourism.

Study participants: They are made up of all employees of the strategic planning unit of the Ministry of Tourism, and given the lack of accurate statistics on preparing workers in that unit, a sample consisting of (20) people who have extensive experience in strategic planning and strategic management was chosen.

\section{Data collection}

The researcher relied on collecting data on the following sources:

- Primary data: The field research method was used using the questionnaire to collect data on the study sample individuals to reveal the relationship between the study variables (strategic leadership) and (tourism activation).

- Secondary data: represented in previous Arab and foreign literature and studies that dealt with the relationship between adopting strategic leadership behavior and activating tourism.

\section{Application of statistical methods to test hypotheses}

Pre-tests: Before starting the application of multiple regression to test the study hypothesis, some pre-tests were performed, to fit the data to the assumptions of the regression analysis, as shown below:

\section{Normality test:}

The data was confirmed to follow the normal distribution by using the test (One-Sample Kolmogorov-Smirnov), and table1 shows that.

Table 1.Test One Sample Kolmogorov-Smirnov for independent and variable variables

\begin{tabular}{|c|c|c|}
\hline variable & Test value(One-Sample Kolmogorov-Smirnov test) & Statistical significance \\
\hline The administrative dimension & 1.036 & 233. \\
\hline The transformational dimension & 722. & 674. \\
\hline The political dimension & 891. & 405. \\
\hline The moral dimension & 764. & 604. \\
\hline Strategic leadership as a whole & 919. & 368. \\
\hline Tourism Promotion & 847. & 470. \\
\hline
\end{tabular}

It can be seen from Table1 that the value of the statistical significance of (One-Sample Kolmogorov-Smirnov test) for all variables was greater than the level of statistical significance $(\alpha \leq 0.05)$, which indicates that these variables follow a normal distribution. Likewise, according to the central tendency theory, which states that if the sample size is greater than (30) and has an arithmetic mean and variance $(2 \sigma)$, then the sampling distribution of the arithmetic mean approaches the normal distribution.

\section{Test the strength of the form:}

To test the strength of the model, several tests were used, namely:

Results of independence test of independent variables:

Pearson correlation coefficients matrix was calculated to find out the relationship between the independent variables, to detect a linear correlation between the independent variables, and Table 2 shows the results of the correlation coefficients between the variables as follows: trust, teamwork culture, shared vision, management practices, shared cultural norms. Depending on the results of Table2, it becomes clear that most of the correlations between the fields of study are significant and have statistical significance at the level of significance $(\alpha \leq 0.01)$, and the results also show the existence of a positive statistically significant correlation between all the independent variables. Thus, it can be judged that there is no complete correlation between the independent variables and each other.

Table 2.Correlation Matrix for Correlation Variables ** Statistically significant at $(\alpha \leq 0.01)$ level

\begin{tabular}{|l|l|l|l|c|}
\hline & The administrative dimension & The transformational dimension & The political dimension & The moral dimension \\
\hline The administrative dimension & 1 & & & \\
\hline The transformational dimension & $\left(^{* *}\right) 770$. & 1 & & \\
\hline The political dimension & $\left(^{* *}\right) 767$. & $\left(^{* *}\right) 877$. & 1 & \\
\hline The moral dimension & $\left(^{* *}\right) 677$. & $\left(^{* *}\right) 805$. & $\left(^{* *}\right) 672$. & 1 \\
\hline
\end{tabular}




\section{Linear Correlation Test (Multicollinearity):}

The linear correlation test was used to ensure that there is no high correlation between the independent variables. By relying on the Variance Inflation Factor (VIF) test and the tolerance test for each of the independent variables, where the independent variables of the model must be independent between them and to make sure of that purpose, we use this test, which is one of the ways to get rid of the problem of linear multiplicity, bearing in mind that the coefficient of variance inflation must not be exceeded for the value (10), and the value of the allowable variance test must be greater than $(0.05)$, and by calculating the previous factors for each independent variable the results obtained were listed in Table 3 as follows:

Table 3. Test of the variance inflation factor and the permissible variance of the study variables

\begin{tabular}{|c|c|c|}
\hline variable & Tolerable variance ( Tolerance) & Contrast the amplification factor VIF \\
\hline The administrative dimension & 336. & 2.972 \\
\hline The transformational dimension & 142. & 7.021 \\
\hline The political dimension & 160. & 6.240 \\
\hline The moral dimension & 323. & 3.101 \\
\hline
\end{tabular}

The value of the permissible variance test for all variables is greater than (0.05), and thus it can be said that there is no high correlation problem between the variables and this enhances the possibility of its use in the model.Through the aforementioned pre-tests, it was found that there is no complete correlation problem between the independent variables and that there is no internal correlation problem between the independent variables. This allows for the continuation of the next stage, which is testing the hypotheses, and thus the multiple regression model is used to study the effect of the independent variables (dimension the administrative dimension, the transformational dimension, the political dimension, the ethical dimension) on the dependent variable (tourism activation).

Hypothesis testing:

Before starting to use linear regression analysis to test the study hypotheses, it was ensured that the data of independent variables were fulfilled for the conditions of regression analysis such as testing the normal distribution and testing the values of correlation between the dimensions of the organizational culture, in addition to making sure that there is no linear correlation problem. The results of these tests indicated the possibility of applying regression analysis. Linearity in extracting the results. The following is a presentation of the results of the linear regression analysis:

- Results of correlation coefficients for the multiple regression model:

Table 4. Model Summary
\begin{tabular}{|c|c|c|c|c|}
\hline Std. The error of the Estimate & Adjusted R2 & R2 & R & Model \\
\hline .169 & .863 & .875 & $.935(\mathrm{~A})$ & 1 \\
\hline
\end{tabular}

a. Predictors: (Constant), the administrative, transformational, political, and moral dimension

b. Dependent Variable: Revitalize Tourism

It can be seen from Table4 that the value of the coefficient of correlation between the independent variable and the dependent variable, which reached its value (0.935), as shown by the value of the coefficient of determination and is defined by (2R) with a value of $(0.875)$, which explains that if an independent variable is added to the model, its value will increase even if there was no significance for the independent variable in the model (the increase of the sum of the squares due to the regression SSR with the constant sum of the total squares SST) and this, the modified coefficient of determination is calculated (Adjusted R2), which takes into account the increase in degrees of freedom, and as described above, its value reached (0.863). Therefore, the independent variables were able to explain $(86.3 \%)$ of the changes occurring in the dependent variable and the remainder due to other factors.

- The overall significance test of the multiple regression model:

Table 5 represents the results of the ANOVA analysis of the significance of the regression model:

Table 5. Results of analysis of variance $b$

\begin{tabular}{|l|c|c|c|c|c|}
\hline Source of variance & sum of squares & degree of freedom & average of squares & F & Sig \\
\hline Regression & 14.454 & 5 & 2.891 & 75.324 & $(\mathrm{a}) 0.000$ \\
\hline Residuals & 2.072 & 54 & 038. & & \\
\hline Total & 16.526 & 59 & & & \\
\hline
\end{tabular}

Table 5 illustrates the analysis of variance, which aims to find the explanatory power of the model as a whole using the statistician (F).

The null hypothesis: There is a statistically significant effect at the level of $(\alpha<05.0)$ significance of the strategic leadership on the revitalization of tourism in Jordan.From what Table 5 shows, it becomes evident that there is a high significance for $(F)$ test estimated at (75.324) and the level of significance estimated at ( $\mathrm{Sig}=0.000)$ less than the level of significance $(\alpha \leq 0.05)$. From this standpoint, the main null hypothesis is accepted, whereby the independent variables combined to affect the dependent variable, as the independent variables interpreted an amount $(86.3 \%)$ of the dependent variable. Thus, it can be said that there is at least one independent variable of the independent variables affecting the dependent variable, which can be significant, and this is known by testing the significance of the coefficients of the multiple regression equation. Test of the significance of the coefficients of the multiple regression equation:

Table 6 shows the values of the regression coefficients for the estimators and their statistical tests, as shown below:

Table 6. a (Coefficient)

\begin{tabular}{|c|l|c|c|c|c|c|}
\hline Model & & \multicolumn{2}{|c|}{ Unstandardized Coefficients } & Standardized Coefficients & & \\
\hline & & B & Std. Error & Beta & t & Sig. \\
\hline 1 & \multicolumn{1}{|c|}{ (Constant) } & 412. & 211. & & 1.947 & 057. \\
\hline & The administrative dimension & 200. & 085. & 194. & 2.341 & 023. \\
\hline & The transformational dimension & 448. & 104. & 552. & 4.323 & 000. \\
\hline & The political dimension & 102. & 117. & 105. & 872. & 387. \\
\hline & The moral dimension & 075. & 087. & 073. & 865. & 391. \\
\hline
\end{tabular}

First sub-hypothesis test:

- the first sub-null hypothesis: There is a statistically significant effect at the level of $(<05.0)$ significance of the administrative dimension on the revitalization of tourism in Jordan. 
It is clear from Table 7 that the value of $(\mathrm{t})$ reached (2.341), and in statistical terms, it reached (0.025), which is less than the level of significance $(0.05 \leq \alpha)$, and the null hypothesis is accepted.

- The second sub-null hypothesis: There is a statistically significant effect at the level of significance $(05<05.0)$ of the transformational dimension on the revitalization of tourism in Jordan.

It is clear from Table 7 that the value of $(\mathrm{t})$ reached (4.323), and in statistical terms, it reached (0.000), which is less than the level of significance $(0.05 \leq \alpha)$, and so the hypothesis is accepted

- The third sub-null hypothesis: There is a statistically significant effect at the level of $(<05.0)$ significance of the political dimension on the revitalization of tourism.

It is clear from Table 7 that the value of $(\mathrm{t})$ reached $(0.872)$, and in statistical terms, it reached $(0.387)$, which is greater than the level of significance $(0.05 \leq \alpha)$, and the hypothesis is rejected.

- The fourth sub-null hypothesis: There is no statistically significant effect at the level of $(\alpha<05.0)$ significance of the ethical dimension of tourism activation.

It is clear from Table 7 that the value of $(\mathrm{t})$ reached $(0.865)$, and in statistical terms, it reached $(0.391)$, which is greater than the level of significance $(0.05 \leq \alpha)$, and the null hypothesis is rejected.

\section{RESULTS}

The results of testing the main hypothesis and the sub-hypotheses derived from it showed that there is a correlation between the application of strategic management and the activation of the tour leader, and the results of the sub-hypothesis test showed that there is a correlation between each dimension of the strategic leadership and the activation of the tourism sector. Therefore, it can be emphasized that the practice of strategic leadership contributes to revitalizing the tourism sector, and perhaps this confirms that adopting a strategic leadership style enhances the capabilities of tourism institutions to influence others to make voluntary decisions that give to achieving the long-term prospects of success of tourism institutions while preserving financial stability. Different leadership approaches to influence the vision and direction of growth and the potential success of an organization to successfully deal with change. Perhaps the Jordanian Ministry of Tourism has paid attention to this issue since the changes began in the Arab world, starting from the year 2011 when it launched its strategic plan in two phases: (2011-2015) and the second phase (2016-2020), then the strategic vision for the year (2025).

Upon reviewing the previous literature, we find that many studies (Harrington et al., 2011) and (Chatain, 2011) confirmed that adopting a strategic leadership approach enhances the competitiveness of the tourism sector.

\section{Recommendations}

In light of the previous result, the study recommends the following:

1. Training leaders in the Ministry of Tourism on the principles of strategic management in its various dimensions.

2. Establishing a qualified unit in the Ministry of Tourism to follow-up and check developments in the surrounding internal and external environment and analyze their implications for tourism in Jordan.

3. Adopting strategic planning as a basic option to enhance the competitiveness of the tourism sector.

\section{Acknowledgment:}

The author wish to thank Dr. Hisham Smadi for his extraordinary support in this research, and Dr. Aymen Frihat for his expert advice and encouragement.

\section{REFERENCES}

Boljević, A., Premović, J., \& Stojanović-Aleksić, V. (2014). Human resources as a factor of creating competitive advantages for tourism enterprises. TehnikaMenadțent, [Technique-Management], 64(1), 145-150. https://doi.org/10.5937/tehnika1401145B.

Capon, C. (2008). Understanding strategic management, Pearson education limited. New York. Glanz, Jeffrey. What Every Principal Should Know about Strategic Leadership. Corwin Press. USA.

Chatain, O. (2011). Value creation, competition, and performance in buyer-supplier Relationships. Strategic Management Journal, 32(1), 76-102. https://doi.org/10.1002/smj.864.

Covey, S. (2006). Principle-centered leadership. Simon and Schuster, London.

Dalton, P., Nanrivell, C., The Bridge, S., \& Hampson, A. (2000). The Impact of the Hybrid Library on Strategic Management, New Review Of Academic Librarian Ship, London, 6, 61-64. https://doi.org/10.1080/13614530009516801.

Danneels, E. (2011). Trying to become a different type of company: dynamic capability at Smith Corona. Strategic Management Journal, 32(1), 1-31. https://doi.org/10.1002/smj.863.

David, Fred, R. (2005). Strategic Management- Concepts and Cases. $10^{\text {th }}$ ed., Pearson \& Prentice Hall, USA.

Enz, Cathy, A. (2010). Hospitality Strategic Management - Concepts and Cases. $2^{\text {nd }}$ ed., John Wiley \& Sons, Inc., New Jersey, USA

Hamtick, D.C. (2002). Putting Top Managers Back into the Picture. Strategic Management Journal Special Issue, 55(2), 10-24.

Harrington, R., Chathoth, P., Ottenbacher, M., \& Altinay, B. (2011). Strategic management research in hospitality and tourism: past, present and future. International Journal of Contemporary Hospitality Management, 25(5), 778 - 808. https://doi.org/10.1108/IJCHM-12-2013-0576.

Hitt, M.A., Ireland, R.D., \& Hoskisson, R.E. (2012). Strategic Management Cases: Competitiveness and Globalization, South-Western Pub.

Hmieleski, K. M., \& Corbett, A. C. 2006. Proclivity for improvisation as a predictor of entrepreneurial intentions. Journal of Small Business Management, 44(1), 45-63.

Ketchen, D., \& Short, J. (2011). Mastering Strategic Management. Paperback, December, Centre for Open Education, USA.

McGee, J., Thomas, H., \& Wilson, D.C. (2010). Strategy: Analysis and Practice. McGraw-Hill.

Olson, P., \& Shobe, JR.B. (2008). White Rappers and Black Epistemology. The Journal of Popular Culture, 41(6). doi.org/10.1111/j.1540-5931.2008.00561.x

Pisapia, J. (2009). The Strategic Leader- New Tactics for a Globalizing World. Information Age Publishing, USA.

Sammut-Bonnici, T. (2010). Information economy strategies in the mobile telecommunications industry. In Understanding Global Strategy, eds S. Segal-Horn and D. Faulkner, Thomson Learning.

Tavitiyaman, P., Zhang, Q.H., \& Qu, H. (2012). The effect of competitive strategies and organizational structure on hotel performances. International Journal of Contemporary Hospitality Management, 24(1), 140-159. https://doi.org/10.1108/09596111211197845.

Vukotić, S., \& Vojnović, B. (2016). The role and importance of strategic plans in the development of tourism. International Scientific Conference, 2-4 June 2016, Serbia, 118-134.

Wagen, R. (2006). Conversation on Planning: Investigation Relationship Between Strategies. Actions and Performance, PhD. http//wwwlib.umi.com /dissertations/fullcit/3220045

Zhang, X., \& Li, B. (2013). Organizational Culture and Employee Satisfaction: An Exploratory Study. International Journal of Trade, Economics and Finance, 4(1) 48-54. 